\title{
Alcohol prevalence and attitudes among adults and adolescents: Their relation to early adolescent alcohol use in rural communities
}

\author{
Laura DeHaan, PhD and Tina Boljevac, BS \\ Psychology Department of Calvin College
}

\begin{abstract}
Although research has identified numerous neighborhood mechanisms influencing urban adolescent risk behaviors, less is known about how community contexts influence rural adolescents. This study explores perceived controls against adolescent drinking (i.e., tolerance of community adolescent alcohol use), adolescent perceptions of community supportiveness, and the prevalence of community alcohol use exhibited by adolescents and adults. Multilevel analyses were applied to $1,4246^{\text {th }}$ through $8^{\text {th }}$ grade students residing in 22 rural communities in the Northern Plains. Perceptions of tolerance, prevalence, and support from 790 parents, teachers, and community leaders were also collected. Analyses revealed that community supportiveness and controls against drinking reduced both the decision to try alcohol and past month use among early adolescents. Adolescents were more likely to have ever tried alcohol if they lived in a community with higher peer prevalence than higher levels of adult alcohol prevalence, but in communities where peer drinking was lower; adolescents were more likely to have tried alcohol if they lived in a high adult-prevalence community. Perceived peer drinking was not related to past month use.
\end{abstract}

\section{Keywords}

adolescent alcohol use; community effects; rural adolescents

\begin{abstract}
Rural and urban adolescents consume alcohol at similar levels (Puskar, Sereika, Lamb, \& Tusale-Mumford, 2000); with several studies finding that rural adolescents report higher alcohol use (Atav \& Spencer, 2002; National Center on Addiction and Substance Abuse at Columbia University [CASA], 2000). Rural youth begin drinking at similar or earlier ages to urban adolescents (Johnston, Bachman, \& O'Malley, 2000; Mink, Wang, Bennett, Moore, Powell, \& Probst, 2005), are more likely to drink and drive (O'Malley \& Johnson, 1999) as well as report dependency-related symptoms (Mink, et al., 2005). Despite this prevalence, rural alcohol use has not been studied extensively.
\end{abstract}

Alcohol abuse, along with increases in crime and illegal drug use, loss of family farms, and lack of jobs, have been identified by rural adults as serious threats to the future of rural America (The Roper Organization, 1992). These adults also cite a growing sense of powerlessness in responding to these trends. The consequence of these changes was a perceived decrease in social influence and problem solving capacity of rural communities.

As rural adolescents make decisions about alcohol use, they must interpret attitudes and behaviors of friends and peers, as well as determine the overall importance that alcohol plays in community life. They also evaluate sanctions against alcohol placed upon them by parents,

Please address correspondence to the first author, Department of Psychology, Calvin College, 1734 Knollcrest Circle SE, Grand Rapids, MI 49546, ldehaan@calvin.edu. 
schools and peers. Interpreting these multiple messages may be especially challenging in rural environments, where privacy and confidentiality can be more difficult to attain.

The early onset of alcohol use among rural adolescents appears especially problematic, as national studies have revealed that early alcohol use has been linked to higher levels of alcohol use in both late adolescence and adulthood (Barnes \& Welte, 1986; Chassin, Pitts, \& Prost, 2002; Hawkins, Graham, Maguin, Abbott, Hill, \& Catalano, 1997; Tucker, Ellickson, Orlando, Martino, \& Klein, 2005; Wilson, Battistich, Syme, \& Boyce, 2002). One study found that delaying alcohol use onset until after age 13 significantly reduced later abuse (Gruber, DiClimente, Anderson, \& Lodico, 1996).

Individual rural communities have been found to differ substantially in terms of adolescent alcohol use. A study of rural eighth graders found 35\% of eighth graders had tried alcohol in one community, versus $86 \%$ in another (Peters, Oetting, \& Edwards, 1992). Less is known about why such differences exist. Population size has been associated with rural adolescent use, with smaller towns consuming less (Edwards, 1997). Alcohol use also appears to be more negatively affected by rural population decline than population increases (Carman, 1983), and alcohol related norms have also been suggested (Leukefeld, Clayton, \& Myers, 1992).

\section{ALCOHOL RELATED NORMS: COMMUNITY AND PEER INFLUENCES}

Considerable research has explored the relationship between national cultural norms and alcoholic consumption. Patrick (1952) argues that alcohol use "... is primarily a cultural phenomenon and it is in the light of the culture of the group or society that the use of such beverages are to be understood" (p. 87). Holder (1998) describes cultural norms as mechanisms allowing personal behavior to be influenced by friends or social networks. In a study of 69 countries, those societies with attitudes about alcohol that were clearly established, well known, and widely accepted, were more likely to have lower alcohol consumption (Ahlstrom, 1994). Economic development has also been found to influence alcohol consumption, but consumption could not be predicted from economics alone (Holder, 1998; Skog, 1986).

In a comprehensive, multi-national study edited by Heath (1995), cultural norms differed greatly among nations across Europe and North America. For example, in Germany, boys were encouraged to drink both with peers and with adults; excessive drinking was considered a rite of passage. In Italy, alcohol, particularly wine, was seen as nourishment. In the Netherlands it was more common to infrequently drink large quantities, while in Poland it was more common for adolescents to frequently drink small quantities. While highlighting the importance of national cultural norms on adolescent drinking, discrepant values occurring within countries were not identified. It is possible that community norms are even more influential in adolescent alcohol use than national norms.

Larsen and Abu-Laban (1968) described three cultural views regarding tolerance of alcohol use: proscriptive (no drinking allowed), prescriptive (some drinking tolerated, but strong values sanctioning how often and how much), and nonscriptive (no constraints on drinking). In general, drinking was found to be the heaviest in nations with nonscriptive views, followed by prescriptive nations, but individual community differences were not examined, and attitudes regarding general alcohol use were not distinguished from attitudes towards adolescent drinking. Krohn, Akers, Radosevich, and Lanza-Kaduce (1985) found that adolescents in prescriptive and nonscriptive environments consumed the most alcohol, while adolescents in proscriptive communities drank less often, and were less likely to drink heavily.

The study also found perceived norms of the $7^{\text {th }}$ and $12^{\text {th }}$ graders' primary groups (peers, family, and religious groups) were related to personal normative orientations toward alcohol and marijuana, as well as to adolescents' use of those substances. The content of peer norms 
was the best predictor of adolescents' own orientations toward alcohol use; those who thought peer norms were permissive toward alcohol use tended to report the same orientation, while those who thought that peer norms prohibited drinking were more likely to disapprove of it. Perception of the content of adult norms also had considerable impact on adolescents' attitudes toward alcohol use but was secondary to peers' norms (Krohn, Akers, Radosevich, \& LanzaKaduce, 1985). Another study of rural seventh graders found that peer drinking norms predicted both current and perceived future drinking, although perceived adult norms did not (Epstein, Botvin, \& Spoth, 2003).

Non-drinkers and heavy drinkers were more accurate in their ability to estimate peer drinking then moderate drinkers in a study of Finnish adolescents, but increased perceptions of peer use were related to increased personal use for all three categories of drinkers (Lintonen \& Konu, 2004). Those with negative attitudes about alcohol were more likely to overestimate others' use, as were individuals from cultures that restricted alcohol use (Makela, 1997).

Perceptions that close friends and peers were drinking were more closely connected to alcohol use than family involvement in one study of adolescents (Olds \& Thombs, 2001), and perceptions of close friends' drinking were more predictive than perceptions of adolescent peers in general (Thombs, Wolcott, \& Farkash, 1997). The belief that those using alcohol and drugs were likely to have more friends increased use among rural seventh graders (Vicary, Snyder, \& Henry, 2000). Adolescents were more likely to imitate peer use when respondents reported close relations with peers (Rethinam \& Reifman, 2002). Friends' use of alcohol was linked to adolescent use, and personal use was found to change over time in ways parallel to perceived friends' use (Henry, Slater, \& Oetting, 2005). In a longitudinal study, higher levels of friends' substance use led to increased alcohol use, but the reverse (i.e., higher alcohol use leading to seek friends with higher use), was not supported (Sieving, Perry, \& Williams, 2002). Friend approval of alcohol was also linked to perceived diminished potency of alcohol (Martino, Collins, Ellickson, Schell, \& McCaffrey (2006). A study of rural high school students (Jenkins, 2001) which examined perceptions of resistance difficulties when offered alcohol or drugs, found peer pressure cited most frequently as a refusal difficulty by nonusers, but seldom mentioned by heavy users.

Parental support and positive school connections in the 8th grade predicted the formation of positive peer relationships, which in turn inhibited binge drinking in the 10th grade (Coker \& Borders, 2001). Increased community involvement, however, were not found as protective factors. Higher perceived parental involvement was associated, however, with weaker associations between peer influences and alcohol use (Wood, Read, Mitchell, \& Brand, 2004). Simultaneously examining community and peer attitudes and behaviors would be beneficial in understanding the relative importance of these influences.

\section{CONTEXTUAL INFLUENCES IN ALCOHOL USE}

Even though few studies have examined community influences in rural environments (Reiss, 1995), several have examined neighborhood influences on adolescent substance use in urban environments. Factors related to higher substance use among urban adolescents include lower social cohesion, community controls and higher poverty (Duncan, Duncan, \& Strycker, 2002).

Large-scale community variables likely have broad influences on rural adolescent risk-taking as well (Wills, Pierce, \& Evan, 1996). Several studies found increased population in rural communities associated with higher levels and earlier onset of alcohol use (Edwards, 1997). Rural adolescents living in town drank more alcohol than adolescents living in the open country (Donnermeyer, 1992), although other studies have found that these differences disappeared by the twelfth grade (Peters, Oetting, \& Edwards, 1992). However, another study found that 
individuals in lower density communities reported more substance use, as well as more "bootlegging" (Logan, Scheck, \& Leukefeld et al., 1999).

A study of 24 rural schools, including responses from eighth grade students, a sample of their parents, and community leaders (Roski, Perry, McGovern, Williams, Farbakhsh, \& VeblenMortenson, 1997) found that increases in positive community norms, role models and opportunities for non-use predicted decreases in alcohol use. The authors caution that "characterizing communities superficially or simplistically may obscure important differences among communities" (p. 263) and suggest school and community environments may be as important as individual and family factors in predicting use. However, factors associated with positive community norms were not identified.

Several issues have been described that make the study of neighborhood effects challenging (Duncan \& Raudenbush, 1999). By only examining census data, community features more relevant to adolescent development may be ignored. Another problem is one of "simultaneous causation", where studies measure both the neighborhood and outcomes with the same adolescent or parent self-report instruments.

\section{SUMMARY AND CRITIQUE}

Growing up in a rural environment certainly does not protect adolescents from alcohol use, even at early ages. Even though past research has indicated that some rural communities have greater levels of adolescent alcohol use than others, community characteristics explaining this heterogeneity have not been clearly identified. It is also not known if community differences remain significant when attitudes and behaviors of both community adults and adolescents are taken into account. When adult beliefs and practices have been considered, they have usually focused on parents, even though Duncan and Raudenbush (1999) note the reliability of other community leaders in providing community value assessments. Examining rural adolescents within specific community contexts would be important in examining the relative importance of peer and adult beliefs and behaviors.

\section{Objectives of the study}

The goal of this study was to examine individual and community influences for both the decision to try alcohol and past month use, among early adolescents living in rural areas. Specifically, the purpose was to explore the roles of community supportiveness, community alcohol prevalence, peer alcohol prevalence, and controls against drinking in relationship to rural alcohol use. We examined perceptions of adolescents, as well as perceptions of parents, teachers, and other community leaders, in order to simultaneously explore individual and community-level variables, and determine the relative weight of individual and community influences.

\section{METHOD}

\section{Sample Selection}

As part of a larger study examining community influences in rural adolescent drinking, 22 communities were selected from four states that scored among the highest nationally in adolescent (aged 12-17) binge drinking (1999 National Household Survey on Drug Abuse, DHHS, 2000). The four states were: North Dakota (17\% of adolescents reported binge drinking, the highest nationally), South Dakota (17\%), Wyoming (17\%), and Wisconsin (15\%). All four states were in the Northern Plains and had overwhelming Caucasian populations in their rural regions, factors that undoubtedly limit the ability to apply research findings to more diverse rural populations. The homogeneous nature of this broader context does, however, allow us to 
simultaneously examine a number of individual, peer, and community effects within the research design.

Although rural communities are considered as having a population of 2,500 or less (Bureau of the Census, 1993), Scaramella and Keyes (2001) note additional factors that should also be assessed, such as proximity to metropolitan areas and distance from interstate highways. Past studies have used several different conceptualizations of rurality, including ranges of population from 2,500 to 25,000 (Albrecht, Amey, \& Miller, 1996; Scaramella \& Keyes, 2001). In this study, rural communities are defined as having populations of 2,500 or less, not adjacent to interstates, and being at least 30 miles from metropolitan areas,.

\section{Procedure}

Elliott, Wilson, and Huizinga (1996), in a review of studies of neighborhood effects on adolescents, noted that most focus only on economic disadvantage, which generate only mild effects on adolescent development. It is therefore important to examine other community-level factors, such as social controls and support, as well as adolescent and community adult alcohol prevalence. Interviews with key community leaders and surveys of all sixth through eighth grade adolescents were used to assess relationships between community-level variables and adolescent alcohol use.

\section{Community selection}

Communities were selected from all rural towns in the four states according to two additional criteria: the community had one or more schools serving all of their sixth through eighth grade students, and half were at least 75 miles from urban areas. In North Dakota, 101 towns fit these criteria, 108 in South Dakota, 117 in Wisconsin, and 34 in Wyoming, for a total of 360. Of the 22 communities, seven were in North Dakota, seven in Wisconsin, five in South Dakota, and three in Wyoming. Eight communities had experienced significant population loss in the past ten years. Community populations ranged from 319 to 2,485, with an average population of 936.

\section{Research Participants}

Adolescents-All students from the sixth through eighth grades in each community were asked to participate, resulting in 1,424 participants. All schools were surveyed, including private. The adolescent sample was $47 \%$ male, and $82 \%$ Caucasian, $7 \%$ Native American, and $4 \%$ Hispanic. Their average age was 12.48 years, ranging from 11 to 15 years of age (Table 1 provides additional information). The adolescent response rate was $73 \%$, with subjects being equally distributed among grades. Demographic data was not available for non-respondents. Because active parental consent strategies were used in 14 of the 22 communities, it is possible that the actual level of alcohol use is underreported, as the use of active consent strategies has been associated with lower levels of reported alcohol use, particularly for high-risk drinking (Frissell et al. 2004).

Parents-A random $20 \%$ of parents of adolescents in the $6^{\text {th }}$ through $8^{\text {th }}$ grades were also surveyed. Parents were not matched to individual children. The focus of the survey was on general community perceptions in terms of support and economic health, as well attitudes and controls regarding adolescent drinking. Because they were not asked about their own children, it was not problematic if they had more than one child in the sixth through the eighth grade. An attempt to obtain an equal number of fathers and mothers was made. As fathers were found to be less concerned about adolescent drinking than mothers (DeHaan \& Thompson, 2002), it was important to examine both fathers and mothers. In single parent homes, that parent was surveyed, so the number of single parents would accurately represent the community 
population. Stepparents, provided they were living in the child's primary residence, were able to participate in the study.

Community leaders-These individuals were identified by working with schools and community social service agencies. As not every community offers the same services, it was not possible to obtain a completely comparable set of community leaders, but strong efforts were made to acquire similar sets of leaders. All sixth through eighth grade teachers were also asked to participate. Community leaders included: enforcement officers, school principal, social services coordinator, mental health counselor, newspaper editor, mayor, and three clergy. The resulting adult sample was $98 \%$ Caucasian, $42 \%$ male, with $70 \%$ having children under the age of 18 . The average age was 44 years, ranging in age from 20 to 81 . When comparing demographic characteristics of our adult sample to census-based demographics for the 22 communities, our adult sample was similar to the community population. Census data indicates that in the 22 communities, adults were $96 \%$ Caucasian, $49 \%$ male, with an average age of 42 , results very similar to the collected sample. Census data also revealed that $8 \%$ of adults in the 22 communities lived on a farm, while $14 \%$ of our adult sample reported living on a farm. One third of the adult sample was parents, $27 \%$ were teachers, and $40 \%$ were other leaders (see Table 1).

Surveys were used for all participants. Adolescents completed paper and pencil surveys during school time. Adult surveys were administered by telephone, the interview occurring after the adults were informed about the project by letter. Ten dollars was donated to the community middle school for each student and adult that participated.

\section{Dependent Variables}

Lifetime alcohol usage was assessed with one item: "Have you ever tried alcoholic beverages, such as beer, wine, or hard liquor?" Past month alcohol use was assessed with a QuantityFrequency Index (QFI) developed by Armor and Polich (1982). Three questions were asked, "How many days in the past month (30 days) did you drink (beer, wine, hard liquor)?"

Responses ranged from 0-30. Individuals were also asked, "When you had alcohol, on average, how much did you usually drink?" with possible responses ranging from 0 to 7 . Because $28 \%$ of adolescents who reported drinking in the past 30 days did not answer the number of drinks per day question, only the sum of the days per month questions were used. Internal consistency for this scale was .70 .

The distribution of past month alcohol use was highly skewed, with $85 \%$ of the total sample reporting no past month use. Because transforming this variable to normality was impossible, we used modeling procedures designed for count data and frequencies (Atkins \& Gallop, in press; Long, 1997). We used a zero-inflated negative binomial (ZINB) regression to model past month use. Because data were collected within specific communities, a ZINB mixedeffects, or multilevel model was used, which allowed for correlations due to nesting within communities (Yau, Wang, \& Lee, 2003). Analyzes were completed in R version 2.4.0, using code developed by Yau and colleagues.

\section{Independent Variables}

\section{Level-one indicators (adolescent perceptions)}

Community controls against drinking: Larsen and Abu-Laban (1968) suggested three categories of tolerance for adolescent alcohol use: communities that tolerate adolescent alcohol use (nonscriptive), strictly prohibit adolescent alcohol use (proscriptive), or allow a limited amount of use in certain conditions (prescriptive). Other studies (Krohn, Akers, Radosevich, $\&$ Lanza Kaduce, 1982) examined these items with a single item, asking whether they perceived themselves to be prescriptive, proscriptive, or nonscriptive, a strategy not deemed appropriate 
for our study. Ten items were developed for this survey, grouped into three subscales, and were pilot tested on college students and adolescents to refine items. Results indicated that the prescriptive and nonscriptive subscales were highly correlated $(r=.77, p<.001)$, and both were negatively correlated with the proscriptive subscale $(r=-.79$, and $-.75, p<.001$, respectively). This suggests that neither adolescents nor adults perceived differences between slight and no controls towards alcohol use, but rather considered their communities as either being tolerant or non-tolerant. When the proscriptive items were reverse coded, principal component analyses revealed that items loaded onto one factor, accounting for 59\% of variance. Factor loadings ranged from .57 to .91 , with an average factor loading of .76. Items were therefore summed into one continuous score, with high scores meaning increased controls against adolescent drinking. This scale had an internal consistency of .82 among the adolescent sample (one item was deleted to increase reliability). Factor loadings ranged from .28 to .83 in the adolescent sample, with an average factor loading of .63. Unless otherwise indicated, all scales were Likert in type, and responses were summed to create a scale score.

Community supportiveness: This eight-item scale was developed by Chipeur et al., (1999). A sample item was "in this community, we look out for each other" This scale was developed for an urban sample; for this study, items were changed from neighborhood to "community." The scale had an internal consistency of .91, and factor loadings ranging from .66 to .85, with an average loading of .80 .

Peer alcohol prevalence: This scale assessed perceived social norms of peer alcohol use, using a six-item scale (Beck \& Treiman, 1996). Items focused on how often an individual perceived that their classmates were drinking, binge drinking, and riding with someone who had been drinking (an item regarding drinking and driving was deleted as our sample was too young to drive). The scale had an internal consistency of .85 in the validating study, and .90 in our sample (one item deleted to increase reliability). Factor loadings ranged from .84 to .91 , with an average loading of .88.

\section{Level II indicators (adult and adolescent aggregated perceptions)}

Community controls against drinking-The same scale used in the adolescent sample was also used for the adult sample. There was an internal consistency of .92 in the adult sample (the same item deleted in the adolescent sample was also deleted in the adult sample to increase reliability). Factor loadings ranged from .55 to .87 , average loading of .76. Because this variable was a community-level indicator, adult scores were aggregated to create one score for each community. The interclass coefficient for this variable was .91 across communities (indicating a high level of agreement among adults in each community), with a range of $.87-.96$.

Prevalence of community adult alcohol use-This variable assessed from adults with two items: "Do you think alcohol is a part of most adult social events in this community," and "Is alcohol a part of most family gatherings in this community?" The two items were significantly correlated $(r=0.51, p<.001)$ among adults in this study. Adult scores were again aggregated, with an interclass coefficient of .67 across communities, and a range of $.48-.85$.

The eight-item community supportiveness scale (identical to the scale used with adolescents) had an internal consistency of .93 in the adult sample, with factor loadings ranging from .67 to .90 , with an average loading of .82 . As this scale was not related to any of the outcomes in initial analyses, it was dropped from the final models.

Community alcohol prevalence (adolescent scale)-This scale was adapted from a 14 item instrument developed by Beck, Scaffa, Swift, and Ko (1995), measuring the prevalence and acceptability of teenage drinking in the community, whether or not adults provided alcohol 
to teenagers, and awareness of problem drinking behaviors among adults. Sample items included "Do you know anyone (of any age) in this community who was killed or injured in a drunk driving accident?" and "Do you know of parents or adults who let non-family members under 21 consume alcohol in their home?" This survey was originally developed for adults, and four items were selected for adolescents. Even though internal consistency in the adolescent sample was low (alpha $=.52$ ), factor loadings ranged from .55 to .73 , with an average loading of .65. Adolescent scores were aggregated, with an interclass coefficient of .76 across communities, with a range of $.58-.87$.

\section{RESULTS}

There were considerable differences across communities for the dependent variables of lifetime and past month use. Although $47 \%$ of the entire sample had tried alcohol at least once, average community percentages of ever having tried alcohol ranged from 9 to $69 \%$. Community averages of past month use ranged from zero to 14 days (see Table 2). Ten percent of the sample (20\% of those who had tried alcohol) reported binge drinking (consuming three or more drinks at one sitting) at least once.

Table 3 shows the modeled associations between early adolescent individual- and communitylevel predictors and lifetime and past month alcohol use. The first model includes only levelone, or individual predictors. The best fit for both dependent variables included random-effects, implying that there was notable variability across communities for both lifetime and past month use. Both level-one and level-two indicators were standardized with a mean of zero and a standard deviation of one.

\section{Analyses with the dependent variable of lifetime use}

The best fit for this model included random-effects, implying significant variation across rural communities in adolescent lifetime use. All variables were standardized to $M=0$ and $S D=1$. Logistic regression models are fit on the log-odds, or logit, scale, and coefficients are exponentiated, yielding an odds-ratio (OR). An OR of less than 1.0 indicates a negative association with lifetime use, while an OR greater than 1.0 is associated with increased chance of lifetime use.

We considered relationships between community controls, support, and prevalence as perceived by adolescents (see Table 3). All three level-one indicators were significant. When considering level-one indicators only, for each $S D$ increase in adolescent-perceived community controls, there was a $27 \%$ decrease $(O R=0.73, p<.001)$ in the rate of middle school students who reported lifetime use. Perceived community supportiveness also played a protective role. For each $S D$ increase in community support, there was an $18 \%$ decrease $(O R=0.82, p<.001)$ in lifetime use. However, for each $S D$ increase in perceived peer prevalence of adolescent drinking, the rate of having tried alcohol almost doubled $(O R=1.96, p<.001)$.

Full model-Additional community-level indicators were added to create a full model, in order to examine adult and adolescent perceptions of overall community alcohol prevalence, and adult perceptions of controls against adolescent drinking.

In the full model, the effects of level-one indicators did not change in either significance level or direction. Adult perceptions of community alcohol prevalence were significantly and positively related to adolescent lifetime use; for every $S D$ increase in adult-perceived adult drinking, adolescents were 38\% more likely to report ever having tried alcohol $(O R=1.38$, $p<.05)$. However, adolescent perceived community prevalence were slightly related to decreased probability of ever having tried alcohol $(O R=0.50, p<.08)$, at the level of a trend. 
Even though adolescent perceptions of community controls against adolescent drinking were highly related to alcohol use, adult perceptions of these controls had no significant relation to lifetime use $(O R=1.02, p=.55$, n.s.). In examining interaction effects, the effects of adultperceived community alcohol prevalence were only significant in communities with lower levels of peer prevalence $(O R=0.85, p<.05)$, as peer prevalence increased, the effects of living in a high adult-prevalence community disappeared.

\section{Analyses with the dependent variable of past month alcohol use}

There was also considerable variation across towns in frequency of past month use, indicating the need for a random-effects model. Count regression models, including the negative binomial model, were fit on a log-scale. For the past month use models, which employed a ZINB regression, an $e^{\beta}$ of greater than 1.0 is associated with higher levels of past month use, while an $e^{\beta}$ of less than 1.0 indicates less past month use.

We examined adolescent perceptions in relation to past month use, using only level-one, or individual indicators (see Table 3). Contrary to lifetime use, perceptions of community controls were not significantly related to past month use (exp. $b=1.37, p=.08)$. Community supportiveness was an even stronger deterrent to past month use than lifetime use, as each $S D$ increase in supportiveness was associated with almost halving past month use (exp. $b=$. $52, p<.001)$. Perceived peer drinking was significantly related to past month use (exp. $b=1.28$, $p<.01)$, although this relationship was not as strong as it was for lifetime use.

Full model-Additional indicators were added to the full model, which examined both adolescent and adult community-aggregated perceptions. The same level-two indicators were entered into this model as for the lifetime use full model. When these community-level indicators were entered into the model, perceived peer drinking was no longer significantly related to past month use (exp. $b=1.23, p=.06$, n.s.). Adult perceptions of community prevalence related to lower levels of past month use (exp. $b=0.38, p=.001$,), as each $S D$ increase in adult-perceived prevalence was related to a $62 \%$ decrease in past month use. Adolescent perceptions of overall community prevalence were not significantly related to past month use (exp. $b=0.48, p=.50$, n.s.). Adult perceptions of controls against adolescent drinking were significantly related to past month use; each $S D$ increase in adult-perceived controls was associated with a $31 \%$ decrease in past month use (exp. $b=0.69, p<.001)$.

One of the examined interactions was significant: the interaction between adult-perceived community drinking and adolescent-perceived peer drinking (exp. $b=1.28, p<.05)$. At lower levels of peer prevalence, adult-perceived prevalence was not significant. However, at higher levels of peer prevalence, moderate adult perceptions related to the highest level of actual drinking. Higher adult-perceived drinking was related to slightly less actual drinking.

\section{DISCUSSION}

Rural adolescent alcohol use has not been studied extensively, even though alcohol use in rural areas is widespread. The influence of both adolescent and adult attitudes and behaviors has not been widely examined, or why adolescents in some rural communities are more likely to initiate alcohol use so much earlier than in others. Our study sought to explore both individual and community level factors in relation to these differences. Among the very rural Northern Plains communities in our study, alcohol use was extensive, with half of adolescents reporting lifetime use, and $15 \%$ reported drinking in the past month. Over $10 \%$ of these middle school students reporting binge drinking at least once. Communities differed widely in terms of alcohol use, with average lifetime use ranging from $9 \%$ to $69 \%$. Past month use also varied considerably, with ranges averaging 0 to 14 drinks per month, underscoring the importance of community 
context among rural adolescents. Rural students are not a homogeneous group, and context was found an important characteristic in rural environments, as it has in urban contexts.

Even though community supportiveness (as perceived by adolescents) significantly reduced both lifetime and past month use, different factors appeared to be related to the decision to try alcohol and the quantity of alcohol consumed. Fewer adolescent-perceived controls against drinking, perceptions that peers were drinking more, and higher perceptions of overall community drinking, all increased the likelihood that adolescents had tried alcohol. Different factors linked to drinking frequency however, as perceived peer drinking was not significant, but adult-perceived controls against drinking were related to lower past month use. Surprisingly, adolescent perceived perceptions of higher controls against drinking was associated with increased past month use, and adult perceptions of increased community alcohol prevalence was associated with less past month use.

Adult-perceived community supportiveness to adolescents was unrelated to early adolescent alcohol use. However, adolescent-perceived community supportiveness and adult-perceived controls against drinking were related to reductions in both lifetime as well as past month use. Living in a community that adolescents perceived as both supportive and exhibited firm discipline was effective in lowering alcohol use among rural adolescents. Just as authoritative parenting, characterized by high levels of support and discipline (Baumrind, 1989) appears effective in lowering adolescent risk behavior, an authoritative community may also have the potential to lower rates of both lifetime and past month use.

Unlike other studies, peer prevalence was not related to increased past month use, even though it was the strongest predictor of the decision to try alcohol. For these rural adolescents, peer behavior was more influential in terms of lifetime use than in the amount of alcohol consumed. It is possible that peer associations may increase among students in senior high school, but is also possible that, as found by Donnermeyer (2006), the influence of peers in rural contexts was not as strong as in other environments.

Peer prevalence was more linked to lifetime use than was overall community prevalence (as perceived by either adolescents or adults). The relationship between peer and community prevalence was complex, in that in communities where peer drinking was low, adolescents were more likely to have tried alcohol when living in a high prevalence community. As peer prevalence increased, adult perceptions no longer significantly predicted lifetime use. Living in a high peer-prevalence community appeared to overshadow adult behaviors. However, in terms of past month use, adolescents were most likely to drink when living in communities where adults reported moderate levels of community prevalence, perhaps because adults reporting higher prevalence may also have exhibited greater vigilance. As adult and adolescent perceptions were related to different outcomes, additional study should focus on these complex relationships.

Adolescent-perceived controls were related to decreased lifetime use, but increased past month use. Growing up in a context where it was perceived that adults monitored and disciplined alcohol use were effective in lowering lifetime use, but these perceptions certainly did not decrease the amount and frequency of drinking. It is possible that students engaging in higher levels of drinking experienced more community sanctions or punishments related to alcohol, and were thus more likely to report higher controls.

Adult-perceived controls against drinking were associated with decreased past month use. This is noteworthy, as these controls appeared effective in reducing heavier levels of drinking. Even though adolescent and adult perceptions of community controls were significantly correlated $(r=.48, p<.05)$, these perceptions were not related to actual drinking in similar ways, highlighting the importance of multi-faceted community assessment tools. This is especially 
true as several of adult and adolescent perceptions of community life were related to alcohol use in different ways.

\section{Limitations of current study}

The adolescents and community leaders in our study came from the Northern Plains, and similar to their state populations, minorities were clearly under-represented. Even though adolescents from the Northern Plains are among the highest in terms of adolescent alcohol use, results from this study cannot be generalized to all rural communities. It was also limiting that parental responses were not linked to individual children, thus familial attitudes and drinking-related behaviors could not be examined. Studies of high school students, young adults not attending college and living in rural areas, and longitudinal studies, would greatly aid in our understanding of community influences in alcohol use.

\section{Implications for school and community officials}

Community leaders may need little reminding that alcohol use is a compelling problem in rural communities, but may be gratified to learn that community efforts to increase both support and discipline towards adolescents can relate to lower levels of early adolescent alcohol use. The importance of perceived supportiveness in reducing lifetime and past month use was striking, as were perceptions of high controls in reducing lifetime use. Adults in the community who created a supportive environment for middle school adolescents were also more likely to live in communities with lower levels of alcohol use. Peer pressure was not the strongest predictor of alcohol use, particularly past month use. Perceptions that adults were supportive and adult perceptions of controls were more closely related to past month use than was peer prevalence.

This study underscores the considerable diversity present in rural communities, even in the relatively homogeneous area of the Northern Plains. Examining community differences remains an important area for future exploration. Identifying factors that lead adolescents and adults to perceive their communities as more effective in controlling adolescent alcohol use, as well as being more supportive, would aid efforts in lowering alcohol use in rural areas. Further study into the complex relationship between peer and community prevalence would also be useful. Finally, more study is needed to explain how alcohol use in middle school translates into later alcohol use in rural areas within specific rural community contexts.

\section{Acknowledgments}

The authors would like to thank David Atkins, Paul Groenewal, Rachel Matthias, and the Iowa State University Institute of Survey Statistics and Methodology for help in data collection and analysis. This project was funded by a grant from the National Institute of Alcohol Abuse and Alcoholism (\# R01AA14390).

\section{References}

Ahlstrom S. Variations in drinking norms by subculture and demography. Contemporary Drug Problems 1994:211-221.

Albrecht SL, Amey C, Miller MK. Pattern of substance abuse among rural black adolescents. Journal of Drug Issues 1996;26:751-781.

Armor, DJ.; Polich, JM. Measurement of alcoholic consumption. In: Pattison, EM.; Kaufman, E., editors. Encyclopedic handbook of alcoholism. New York: Gardner; 1982. p. 72-81.

Atav S, Spencer GA. Health risk behaviors among adolescents attending rural, suburban, and urban schools: A comparative study. Family and Community Helath 2002;25:53-64.

Atkins DC, Gallop RJ. Abuse, criticism, and drug use: How should we model negative behaviors in marital and family research? (in press).

Atkins DC. Using multilevel models to analyze marital and family treatment data: Basic and advanced issues. Journal of Family Psychology 2005;19:98-110. [PubMed: 15796656] 
Barnes GM, Welte JW. Patterns and predictors of alcohol use among 7-12 ${ }^{\text {th }}$ grade students in New York State. Journal of Studies on Alcohol 1986;47:53-62. [PubMed: 3485740]

Baumrind, D. Rearing competent children. In: Damon, W., editor. Child development today and tomorrow. San Francisco: Jossey-Bass; 1989. p. 349-378.

Beck KH, Treiman KA. The relationship of social context of drinking, perceived social norms, and parental influence to various drinking patterns of adolescents. Addictive Behaviors 1996;21:633-644. [PubMed: 8876762]

Beck KH, Scaffa M, Swift R, Ko M. A survey of parent attitudes and practices regarding underage drinking. Journal of Youth and Adolescence 1995;24:315-334.

Blum, RW.; Rinehart, PM. Reducing the risk: Connections that make a difference in the lives of youth. Minneapolis, MN: University of Minnesota; 1997.

Bureau of the Census. Statistical abstract of the United States, 1993: The national data book. Washington, DC: U.S. Department of Commerce; 1993.

Carman RS. Population change and public drinking in three rural communities. International Journal of Social Psychiatry 1983;42:161-167.

Chassin L, Pitts SC, Prost J. Binge drinking trajectories from adolescent to emerging adulthood in a highrisk sample: Predictors and substance abuse outcomes. Journal of Consulting and Clinical Psychology 2002;70:67-78. [PubMed: 11860058]

Chipuer HM, Pretty GH, Delorey E, Miller M, Powers T, Rumstein O, Barnes A, Cordasic N, Laurent $\mathrm{K}$. The neighbourhood youth inventory: Development and validation. Journal of Community \& Applied Social Psychology 1999;9:355-368.

Coker JK, Borders LD. An analysis of environmental and social factors affecting adolescent problem drinking. Journal of Counseling and Development 2001;79:200-208.

DeHaan LG, Thompson K. Adolescent and adult alcohol attitudes in a high consumption community. Journal of Drug Education 2003;33:399-413. [PubMed: 15237865]

Donnermeyer J. The use of alcohol, marijuana, and hard drugs by rural adolescents: A review of recent research. Drugs \& Society 1992;7(1-2):31-75.

Donnermeyer J. Urbanity, rurality, and adolescent substance use. Criminal Justice Review 2006;31:337356.

Duncan SC, Duncan TE, Strycker LA. A multilevel analysis of neighborhood context and youth alcohol and drug problems. Prevention Science 2002;3:125-133. [PubMed: 12088137]

Duncan, GJ.; Raudenbush, SW. Neighborhoods and adolescent development: How can we determine the links?. Working paper from the Joint Center on Poverty Research; 1999.

Edwards, RW. Drug and alcohol use among youth in rural communities. In: Robertson, EB.; Sloboda, Z.; Boyd, GM.; Beatty, L.; Kozel, NJ., editors. Rural substance abuse: State of knowledge and issues. Rockville, MD: National Institute of Health; 1997.

Elder, GH.; Conger, RD. Children of the land: Adversity and success in rural America. Chicago, IL: University of Chicago Press; 2000.

Elliot DS, Wilson WJ, Huizinga D. The effects of neighborhood disadvantage on adolescent development. Journal of Research in Crime and Delinquency 1996;33:389-426.

Epstein JA, Botvin GJ, Spoth R. Which psychosocial factors are related to drinking among rural adolescents? Journal of Child and Adolescent Substance Abuse 2003;13:19-35.

Frissel KC, McCarthy DM, D’Amico EJ, Metrick J, Ellingstad TP, Brown SA. Impact of consent procedures on reported levels of adolescent alcohol use. Psychology of Addictive Behaviors 2004;18:307-315. [PubMed: 15631602]

Grant BF, Dawson DA. Age at onset of alcohol use and its association with DSM-IV alcohol abuse and dependence: Results from the National longitudinal alcohol epidemiological survey. Journal of Substance Abuse 1997;9:103-110. [PubMed: 9494942]

Gruber E, DiClimente RJ, Anderson MM, Lodico M. Early drinking onset and its association with alcohol use and problem behavior in late adolescence. Preventive Medicine 1996;25:293-300. [PubMed: 8781007]

Harrell, AV.; Cisin, IH. Drugs in rural America: A special report from the 1979 national survey on drug abuse. Washington DC: George Washington University, Social Research Group; 1980. 
Hawkins JD, Graham JW, Maguin E, Abbott R, Hill KG, Catalano RF. Exploring the effects of age alcohol use initiation and psychological risk factors on subsequent alcohol misuse. Journal of Studies on Alcohol 1997;58:280-290. [PubMed: 9130220]

Heath, DB. International handbook on alcohol and culture. Westport, CT: Greenwood Press; 1995.

Henry KL, Slater MD, Oetting ER. Alcohol use in early adolescence: The effect of changes in risk taking, perceived harm and friends' alcohol use. Journal of Studies on Alcohol 2005;66:275-283. [PubMed: 15957679]

Holder, HD. Alcohol in the community: A systems approach to prevention. New York, NY: Cambridge University Press; 1998.

Jencks, C.; Mayer, SE. The social consequences of growing up in a poor neighborhood. In: Lynn, LE.; McGeary, M., editors. Inner city poverty in the United States. Washington, DC: National Academy Press; 1990.

Jenkins JE. Rural adolescent perceptions of alcohol and other drug resistance. Child Study Journal 2001;31:211-224.

Johnston, LD.; O’Malley, PM.; Bachman, JG. NIH Publication No 00-4690. Rockville, MD: National Institute on Drug Abuse; 2000. The Monitoring the Future national survey results on drug use: Overview of key findings, 1999.

Krohn MD, Akers RL, Radosevich MJ, Lanza-Kaduce L. Norm qualities and adolescent drinking and drug behavior: The effects of norm quality and reference group on using and abusing alcohol and marijuana. Journal of Drug Issues 1982;12:343-359.

Krohn MD, Lanza-Kaduce L, Akers RL. Community context and theories of deviant behavior: An examination of social learning and social bonding theories. The Sociological Quarterly 1985;25:353371.

Larsen DE, Abu-Laban B. Norm qualities and deviant drinking behavior. Social Problems 1968;15:441450.

Leukefeld, CG.; Clayton, RB.; Meyers, JA. Rural drug and alcohol treatment. In: Edwards, RW., editor. Drug Use in Rural American Communities. New York: The Haworth Press, Inc; 1992.

Lintonen TP, Konu AI. The misperceived social norm of drunkenness among early adolescents in Finland. Health Education Research 2004;19:64-70. [PubMed: 15020546]

Logan TK, Schenck JE, Leukefeld CG, Meyers J, Allen S. Rural attitudes, opinions, and drug use. Substance Use \& Misuse Special Issue: Symposium on rural/urban continuum 1999;34:545-565.

Long, JS. Regression Models for Categorical and Limited Dependent Variables. Thousand Oaks, CA: Sage Publications; 1997.

Maggs JL, Hurrelmann K. Do substance use and delinquency have differential associations with adolescents' peer relations? International journal of behavioral development 1998;22:367-388.

Makela K. Drinking, the majority fallacy, cognitive dissonance, and social pressure. Addiction 1997;92:729-736. [PubMed: 9246800]

Manke, B.; Fried, H. Predicting children's well being: Do neighborhood characteristics matter?. Paper presented at the Society for Research on Adolescence; Chicago. 2000.

Martino SC, Collins RL, Ellickson PL, Schell TL, McCaffrey D. Socio-environmental influences on adolescents' alcohol outcome expectancies: A prospective analysis. Addiction 2006;101:971-983. [PubMed: 16771889]

McIntosh, J.; Grant, K.; Shah, S. Neighborhood risk and behavior problems among low-income urban African American adolescents: Social embeddedness as a moderator? Paper presented at the Society for Research on Adolescence; Chicago. 2000.

Mink, M.; Wang, JY.; Bennett, KJ.; Moore, CG.; Powell, MP.; Probst, JC. Early alcohol use, rural residence, and adulthood employment. Columbia, SC: South Carolina Rural Health Research Center; 2005.

National Center on Addiction and Substance Abuse (CASA) at Columbia University. No place to hide: Substance abuse in mid-size cities and rural America. New York, NY: National Center on Addiction and Substance Abuse (CASA) at Columbia University; 2000.

O’Malley PM, Johnson LD. Drinking and driving among US high school seniors, 1984-1977. American Journal of Public Health 1999;89:678-684. [PubMed: 10224978] 
Olds RS, Thombs DL. The relationship of adolescent perceptions of peer norms and parent involvement to cigarette and alcohol use. Journal of School Health 2001;71:223-228. [PubMed: 11512489]

Osgood WD, Chambers JW. Social Disorganization outside the Metropolis: An Analysis of Rural Youth Violence. Criminology 2000;38:81-115.

Patrick, CH. Alcohol, culture, and society. Durham, NC: Duke University; 1952.

Peters, VJ.; Oetting, ER.; Edwards, RW. Drug use in rural communities: An epidemiology. New York: Haworth Press; 1992.

Puskar KR, Sereika S, Lamb J, Tusale-Mumford K. Substance use among high school students in rural Pennsylvania. Journal of Addictions Nursing 2000;12:55-63.

Reiss, AJ. Community influences on adolescent behavior. In: Rutter, M., editor. Psychosocial disturbances in young people. Cambridge, NY: Cambridge University Press; 1995. p. 305-32.

Rethinam, V.; Reifman, A. Does closeness to parents and peers regulate college students' modeling of their drinking?. Poster presented at the Ninth Biennial Meeting of the Society for Research on Adolescence; New Orleans, LA. 2002 Apr.

Rojewski JW. Impact of at-risk behavior on the occupational aspirations and expectations of male and female adolescents in rural settings. Journal of Career Development 1995;22:33-48.

Roski J, Perry CL, McGovern PG, Williams CL, Farbakhsh K, Veblen-Mortenson S. School and community influences on adolescent alcohol and drug use. Health Education Research 1997;12:255266. [PubMed: 10168577]

Rountree PW, Clayton RR. A contextual model of adolescent alcohol use across the rural-urban continuum. Substance Use and Misuse 1999;34:495-519. [PubMed: 10210090]

Scaramella LV, Keyes AW. The social contextual approach and rural adolescent substance use: Implications for prevention in rural settings. Clinical Child and Family Psychology Review 2001;4:231-251. [PubMed: 11783740]

Sampson RJ. Collective regulation of adolescent misbehavior: Validation results from eighty Chicago neighborhoods. Journal of Adolescent Research 1997;12:227-244.

Sieving RE, Perry CL, Williams CL. Do friendships change behaviors, or do behaviors change friendships? Examining paths of influence in young adolescents' alcohol use. Journal of Adolescent Health 2002;26:27-35. [PubMed: 10638715]

Skog O. An analysis of divergent trends in alcohol consumption and economic development. Journal of Studies on Alcohol 1986;47:19-25. [PubMed: 3515051]

Thombs DL, Wolcott BJ, Farkash LGE. Social context, perceived norms and drinking behavior in young people. Journal of Substance Abuse 1997;9:257-267. [PubMed: 9494953]

The Roper Organization, Inc. Public attitudes toward rural America and rural electric cooperatives. Washington, D.C: National Rural Electric Cooperative Association. Agricultural Communications Documentation Center; 1992 Jun. Doc.ID\# CO6373

Tucker JS, Ellickson PL, Orlando M, Martino SC, Klein DJ. Substance use trajectories from early adolescent to emerging adulthood: A comparison of smoking, binge drinking, and marijuana use. Journal of Drug Issues 2005;35:307-332.

Vicary JR, Synder AR, Henry KL. The effects of family variables and personal competencies on the initiation of alcohol use by rural seventh grade students. Adolescent \& Family Health 2000;1:21-28.

Wills TA, Pierce JP, Evans RI. Large-scale environmental risk factors for substance use. American Behavioral Scientist 1996;39:808-822.

Wilson N, Battistich V, Syme SL, Boyce WT. Does elementary school alcohol, tobacco, and marijuana use increase middle school risk. Journal of Adolescent Health 2002;30:442-447. [PubMed: 12039514]

Wood MD, Read JP, Mitchell RE, Brand NH. Do parents still matter? Parent and peer influences on alcohol involvement among recent high school graduates. Psychology of Addictive Behaviors 2004;18:19-30. [PubMed: 15008682]

Yau KKW, Wang AH, Lee AH. Zero-inflated negative binomial mixed regression modeling of overdispersed count data with extra zeros. Biometrical Journal 2003;45:437-452. 
Table 1

Characteristics of Adolescent and Adult Samples

\begin{tabular}{|c|c|c|}
\hline \multicolumn{3}{|l|}{ Characteristics of Adolescent Sample } \\
\hline & $\mathbf{n}$ & Percent \\
\hline \multicolumn{3}{|l|}{ Grade } \\
\hline 6 & 441 & 32 \\
\hline 7 & 486 & 35 \\
\hline 8 & 478 & 33 \\
\hline \multicolumn{3}{|l|}{ Race (several indicated more than one) } \\
\hline White & 1268 & 82 \\
\hline Hispanic & 57 & 4 \\
\hline African American & 16 & 1 \\
\hline Native American & 107 & 7 \\
\hline Asian & 29 & 2 \\
\hline \multicolumn{3}{|l|}{ Place of Residence } \\
\hline Town & 760 & 53 \\
\hline Farm & 264 & 19 \\
\hline Country, not farm & 393 & 28 \\
\hline \multicolumn{3}{|l|}{ Characteristics of Adult Sample } \\
\hline Parent of a 6 th, 7 th, or 8 th grader & 244 & 31 \\
\hline Teacher & 216 & 27 \\
\hline Principal & 24 & 3 \\
\hline School counselor & 19 & 2 \\
\hline Law enforcement & 24 & 3 \\
\hline School/Community Administration & 43 & 5 \\
\hline Pastor/Youth Minister & 61 & 8 \\
\hline Coach/Youth club leader & 61 & 8 \\
\hline Business owner that employs youth & 21 & 3 \\
\hline Other school employee & 59 & 8 \\
\hline Attends youth activities & 18 & 2 \\
\hline
\end{tabular}


